Assistant Professor Mohsen KHEZRI, PhD (Corresponding author)

E-mail: m.khezri@basu.ac.ir

Faculty of Economics and Social Sciences, Bu-Ali Sina University, Iran

Assistant Professor Reza GHAZAL, PhD

E-mail: rghaz046@uottawa.ca

Policy Advisor, Environment and Climate Change, Canada

Assistant Professor Somayeh SHOKRAVI, PhD

E-mail: Shokravi@iiau.ac.ir

Department of Management and Accounting, Islamshahr Branch

Islamic Azad University, Iran

\title{
STOCK RETURNS AND INFLATION IN US: A MS-FITGARCH MODEL
}

Abstract. This paper presents a new perspective on the Fisher hypothesis in relation to the real stock returns and expected inflation, by using the monthly real stock returns for the S\&P 500 and inflation rates in US from January 1990 to December 2016. Results suggest a strong evidence of regime-dependence of stock market return for a two-regime MS-FITGARCH $(1,1)$. The estimation results for regime 1 are consistent with low variance-high mean regime (expansion phase), while regime 2 is consistent with high variance-low mean regime (recession phase). Furthermore, the estimated coefficient of first lag of inflation in mean equation is negative and significantly different from zero in expansion phase, but insignificant in recession phase, confirming the results indicated by Fisher hypothesis only in recession phase. Results show that first lag of inflation does not affect the probability of staying in expansion or recession phases.

Keywords: Fisher Hypothesis, MS-FITGARCH, Regime Switching.

\section{JEL Classification: G1, E44}

\section{Introduction}

Fisher hypothesis (1930) states that there is no relationship between the real stock returns and expected inflation, and therefore, common stocks can be used as a hedge against expected inflation. Since then until the mid-seventies, a number of economists believed that real stock returns and expected inflation should be positively correlated with each other or at least not be negatively correlated.

Even though some studies have indicated that there is correlation between returns and inflation for the UK after the WWII, however, several studies have 
found that such a relationship was negative. According to Modigliani and Cohn (1979), permanent inflation diminishes real prices of stocks because the factors suffer from inflation illusion. Inflation illusion leads to a sort of inability to exactly determine the factors of the nominal and real interest rates.

Fama (1981) presented an explanation for this negative relationship through examining a relationship between stock returns and inflation and real output. He showed that the relationship between inflation and real output is negative, on one hand, and the relationship between real output and real stock returns is positive, on the other. The existence of such negative relationship confirmed by other researchers (Kryzanowski and Rahman, 2009). According to these studies, the inflation affects stock returns through two channels of permanent and temporary components of inflation and depending on the source of fluctuations; the volatility of prices has different effects on production. The permanent component originated from supply shocks creates movements in real activities (such as changes in the business situations or energy prices). Through this channel, any change in inflation negatively affects production. Basically, supply disruption impacts the permanent component of inflation and reflects changes in real economic activities and may lead to a negative relationship between stock returns and inflation.

On the other hand, the temporary component of inflation is a result of demand shock, representing the temporary and non-expected changes in inflation caused by monetary policies, changes in government spending, and other factors on the demand side. Through this channel, disruption in demand causes temporary inflation which may positively affect the stock returns. Thus, the answer to this question that whether inflation affects the real return of stocks negatively or positively is somewhat ambiguous. Understanding the impact of inflation on the real return provides tools for risk management in stock markets by the hedge funds and pension providers and also the policy makers.

Since linear models are not able to capture asymmetries, Markov switching regression model has been widely used to clarify the behaviors of regime change in stock markets (Hamilton and Susmel, 1994). Very recent studies have used MSEGARCH models with the capability of modeling clusters of volatility and capturing the asymmetries. These studies confirmed the existence of the volatility switching regimes in stock returns. Henry (2009) presented a two-regime MSEGARCH model to investigate the relationship between the short-term interest rates and UK stock market. Aloui and Jammazi (2009), using a two-regime MSEGARCH model studied the relationship between volatilities in the oil market and stock prices for France, UK and Japan. Walid et al. (2011) by using an MSEGARCH model examined the dynamic relationship between the volatility of stock prices and exchange rates for emerging economies.

Financial returns have significant autocorrelations which decay toward zero slower than a short-memory process. Many results have argued that this pattern of the sample autocorrelations suggests that the volatilities of financial 
returns can be represented by long-memory processes. In light of this, the so-called Fractionally Integrated Threshold GARCH (FITGARCH) models have not only the capability of modeling the volatility clusterings and capturing their asymmetries, but also they take into account the characteristic of long-range dependence in the volatility (Lopes and Prass, 2014).

In this paper, we test the relationship between equity returns and inflation using a Markov Switching Fractionally Integrated Threshold GARCH model (MSFITGARCH) with two regimes and explained transition probabilities. This model is an extension of MS-EGARCH model introduced by Henry (2009). It allows the variance of stock returns to switch across different regimes so that the conditional variance within each regime is time-variant and asymmetric with the characteristic of long-range dependence in the volatility. This modeling is partly based on the assumption that stock return may move across different volatility regimes characterized by different perceptions and reactions of market participants to volatility shocks on inflation (see e. g. Wang and Theobald, 2008). In addition, the proposed model is capable of detecting regime dependence in the impact, persistence, long-range dependence in the volatility and asymmetric response to shocks due to the fact that the conditional variance depends on past shocks and the present and past states of the economy (Aloui and Jammazi, 2009). MSFITGARCH model with the characteristic of long-range dependence in the volatility has more flexibility and accuracy than the previous models in modeling the stock return volatility. Therefore, our main contribution would be introducing such flexible model to test the relationship between stock market real rate of return and inflation for the US economy. To our knowledge, such methodology has not been used in the literature.

This study is organized as follows. Section two provides the literature review. Section three presents the theoretical Markov switching models. Section four presents the descriptive statistics briefly. Section five discusses the results, and finally section six presents the conclusions and recommendations.

\section{The Markov Switching Fractionally Integrated Threshold GARCH (MS-FITGARCH) framework}

The Generalized ARCH (GARCH) model of Bollerslev (1986) is based on an infinite ARCH specification which reduces the number of estimated parameters by imposing nonlinear restrictions. The GARCH (p, q) model can be expressed as:

$$
\sigma_{t}^{2}=\omega+\sum_{i=1}^{q} \alpha_{i} \varepsilon_{t-i}^{2}+\sum_{j=1}^{p} \beta_{j} \sigma_{t-j}^{2}
$$

That can easily be rewritten as follows:

$$
\begin{aligned}
& \phi(L) \varepsilon_{t}^{2}=\omega+\beta(L) u_{t} \\
& \text { Where } u_{t}=\varepsilon_{t}^{2}-\sigma_{t}^{2}
\end{aligned}
$$

For stationary time series, AFC decline to zero exponentially with increasing in lags but for non-stationary time series AFC is convergent to one for all lags. There are some time series that their AFC decline slowly to zero in the 
form of polynomial function with increasing in lags, labeled as time series with long-memory, for which the effects of a shock can take a considerable time to decay. Therefore, the distinction between stationary and unit root processes seems to be far too restrictive. Indeed, the propagation of shocks in a stationary process occurs at an exponential rate of decay (and so it only captures the short-memory), while for an unit root process the persistence of shocks is infinite.

The high persistence in GARCH models suggests that the polynomial $\phi(z)=0$ may have a unit root, which gives rise to the integrated GARCH (IGARCH) model (See Nelson, 1990 for which the unconditional variance does not exist). To allow for high persistence and long memory in the conditional variance while avoiding the complications of IGARCH models, we extend the ARMA (m, q) process in (1) to a FARIMA (m, d, q) process as follows:

$$
\phi(L)(1-L)^{d} \varepsilon_{t}^{2}=\omega+\beta(L) u_{t}
$$

where all the roots of $\phi(z)=0$ and $\beta(z)=0$ lie outside the unit circle. When $d=0$, this reduces to the usual GARCH model, when $d=1$, it becomes the IGARCH model, and when $0<d<1$, the fractionally differenced squared residuals, follow a stationary ARMA $(\mathrm{m}, \mathrm{q})$ process. The above FARIMA process for $\varepsilon_{t}^{2}$ can be rewritten in terms of the conditional variance $\sigma_{t}^{2}$ as follows:

$$
\beta(L) \sigma_{t}^{2}=\omega+\left[\beta(L)-\phi(L)(1-L)^{d}\right] \varepsilon_{t}^{2}
$$

To mimic the behavior of the correlogram of the observed volatility, Baillie, Bollerslev, and Mikkelsen (1996) refered to the above model as the fractionally integrated GARCH, or FIGARCH (m, d, q) model. When $0<d<1$, the coefficients in $\phi(L)$ and $\beta(L)$ capture the short-run dynamics of volatility, while the fractional difference parameter $\mathrm{d}$ models the long-run characteristics of volatility.

Another GARCH variant that is capable of modeling leverage effects is the Threshold GARCH (TGARCH) model that is defined as follows:

$$
\sigma_{t}^{2}=\omega+\sum_{i=1}^{q}\left(\alpha_{i} \varepsilon_{t-i}^{2}+\gamma S_{t-i} \varepsilon_{t-i}^{2}\right)+\sum_{j=1}^{p} \beta_{j} \sigma_{t-j}^{2}
$$

where $S_{t-i}$ is a dummy variable that take the value 1 when $\varepsilon_{t-i}$ is negative and 0 when $\varepsilon_{t-i}$ is positive. $\gamma$ is the so-called asymmetry parameter, which permits positive and negative disturbances to contribute differently to the conditional variance. In this model, it is assumed that the impact of $\varepsilon_{t}^{2}$ on the conditional variance $\sigma_{t}^{2}$ is different when $\varepsilon_{t}^{2}$ is positive or negative. The original TGARCH model proposed by Zakoian (1994) models uses $\sigma_{t}$ instead of $\sigma_{t}^{2}$. This model is also known as the GJR model.

For simultaneous modeling of long-memory and asymmetry we consider a FITGARCH model by combining TGARCH model and FIGARCH model introduced by Baillie, Bollerslev, and Mikkelsen (1996) as follows:

$$
\beta(L) \sigma_{t}^{2}=\omega+\left[\beta(L)-\phi(L)(1-L)^{d}\right]\left(1+\gamma S_{t}\right) \varepsilon_{t}^{2}
$$

Where $\varphi$ is a $(\mathrm{M} \times 1)$ vector of parameters. In this article, the FITGARCH $(1,1)$ model is considered as: 


$$
\begin{gathered}
y_{t}=f\left(x_{t} ; \vartheta\right)+\varepsilon_{t} \varepsilon_{t} / I_{t-1} \rightarrow D\left(0, h_{t}\right) \\
(1-\beta L) \sigma_{t}^{2}=\omega+\left[(1-\beta L)-(1-\beta L-\alpha L)(1-L)^{d}\right]\left(1+\gamma S_{t}\right) \varepsilon_{t}^{2}
\end{gathered}
$$

Where, in Eq. (7), $f\left(x_{t} ; \vartheta\right)$ is conditional mean, $x_{t}$ is a vector of $\mathrm{M}$ explanatory variables, that may include lagged $y_{t}{ }^{\prime} s^{\prime}, I_{t-1}$ is the information set that contains all information available at time $(\mathrm{t}-1)$, and $\varepsilon_{t}$ is the error term. The conditional variance follows an FITGARCH $(1,1)$ process, as given in Eq. (8). As a conditional distribution, D, the Student-t proposed by Bollerslev (1987) is generally used.

Hamilton and Susmel (1994) modified the conditional variance equation to make the conditional variance dependent on the state of the economy. Henry (2009) modeled a two-regime Markov-Switching EGARCH model. The basic MSFITGARCH $(1,1)$ model can be modified as follows:

$$
y_{t}=\mu_{i t}+\varepsilon_{t} \varepsilon_{t} / I_{t-1} \rightarrow D\left(0, h_{i, t}\right)
$$

$$
\left(1-\beta_{i} L\right) \sigma_{i, t}^{2}=\omega_{i}+\left[\left(1-\beta_{i} L\right)-\left(1-\beta_{i} L-\alpha_{i} L\right)(1-L)^{d_{i}}\right]\left(1+\gamma_{i} S_{t}\right) \varepsilon_{t}^{2}(10)
$$

By assuming the existence of two states, $(i=2)$, the two regimes can be displayed by a latent variable $s_{t}$, taking on two values, 0 (first regime) and 1 (second regime), depending on the state of the economy.

The transition between the states is governed by a first order Markov process as follows (Hamilton, 1989):

$$
\begin{gathered}
\mathrm{P}\left(\mathrm{S}_{\mathrm{t}}=0 / \mathrm{S}_{\mathrm{t}-1}=0\right)=\mathrm{p}_{00} \\
\mathrm{P}\left(\mathrm{S}_{\mathrm{t}}=0 / \mathrm{S}_{\mathrm{t}-1}=1\right)=1-\mathrm{p}_{11} \\
\mathrm{P}\left(\mathrm{S}_{\mathrm{t}}=1 / \mathrm{S}_{\mathrm{t}-1}=0\right)=1-\mathrm{p}_{00} \\
\mathrm{P}\left(\mathrm{S}_{\mathrm{t}}=1 / \mathrm{S}_{\mathrm{t}-1}=1\right)=\mathrm{p}_{11}
\end{gathered}
$$

With $\mathrm{p}$ is the probability that the economy switches at time $\mathrm{t}$ from state 1 to state 0or vice versa. These transition probabilities can be summarized in a $(2 \times 2)$ matrix as $\left[\begin{array}{cc}p_{00} & 1-p_{11} \\ 1-p_{00} & p_{11}\end{array}\right]$, where the probabilities are fixed. The logistic functional form, then, can be defined as:

$$
\mathrm{p}_{00}=\frac{e\left(\theta_{0}\right)}{1+\mathrm{e}\left(\theta_{0}\right)} \text { and } \mathrm{p}_{11}=\frac{\mathrm{e}\left(\partial_{0}\right)}{1+\mathrm{e}\left(\partial_{0}\right)}
$$

According to Hamilton (1989), the MS-FITGARCH can be estimated using Maximum Likelihood. As noted by Filardo and Gorgon (1998), with fixed transition probabilities, the expected durations do not vary over the cycle. This means that exogenous shocks, macroeconomic policies and the economy's own internal propagation mechanisms do not influence the probability of how long an expansion or contraction will persist. To resolve this problem, the time-varying transition probabilities are included in the model. The variations in the transition probabilities would produce variations in the expected durations (Filardo and Gorgon, 1998). By allowing the transition matrix (P) to be explained by reflecting 
information about where the economy is advancing via variable $x_{t-1}$, the timevarying transition matrix $\mathrm{P}(\mathrm{t})$ can be formulated as follows:

$$
P(t)=P\left(s_{t}=\frac{j}{s_{t-1}}=i, x_{t-1}\right)=\left[\begin{array}{cc}
p_{00}^{t}\left(x_{t-1}\right) & 1-p_{11}^{t}\left(x_{t-1}\right) \\
1-p_{00}^{t}\left(x_{t-1}\right) & p_{11}^{t}\left(x_{t-1}\right)
\end{array}\right\rfloor
$$

In this equation, $x_{t-1}$ is the information variable (s), upon which the evolution of the unobserved regime will be depending on. In our analysis, it is possible to investigate whether first lag of inflation (as proxy for expected inflation), i.e. inflation $_{t-1}$, influence not only the mean and the variance of the real stock return $\left(y_{t}\right)$ but also the regime-switching probabilities. Thus, MSFITGARCH $(1,1)$ model with explained transition probabilities can be written as follows:

$$
\begin{aligned}
& y_{t}=\mu_{i t}+\eta_{i} \text { inflation }_{t-1}+\varepsilon_{t} \varepsilon_{t} / I_{t-1} \rightarrow D\left(0, h_{i, t}\right) \\
& \left(1-\beta_{i} L\right) \sigma_{i, t}^{2}=\omega_{i}+\left[\left(1-\beta_{i} L\right)-\left(1-\beta_{i} L-\alpha_{i} L\right)(1-L)^{d_{i}}\right]\left(1+\gamma_{i} S_{t}\right) \varepsilon_{t}^{2}+ \\
& \lambda_{i} \text { inflation }_{t-1}
\end{aligned}
$$

According to Filardo (1994), then the transition probabilities are given by:

$$
\begin{aligned}
& p_{00}^{t}=\operatorname{Pr}\left(s_{t}=0\right)=\frac{e\left(\theta_{0}+\theta_{1} \text { inflation }_{t-1}\right)}{1+e\left(\theta_{0}+\theta_{1} \text { inflation }_{t}\right)}
\end{aligned}
$$

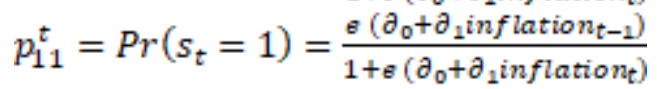

$$
\begin{aligned}
& \text { It follows that: } \\
& \frac{\partial \mathrm{p}_{00}^{\mathrm{t}}}{\partial \mathrm{x}_{\mathrm{t}-1}}=\theta_{1} \mathrm{p}_{00}^{\mathrm{t}}\left(1-\mathrm{p}_{00}^{\mathrm{t}}\right) \\
& \frac{\partial \mathrm{p}_{11}^{\mathrm{t}}}{\partial \mathrm{x}_{\mathrm{t}-1}}=\partial_{1} \mathrm{p}_{11}^{\mathrm{t}}\left(1-\mathrm{p}_{11}^{\mathrm{t}}\right)
\end{aligned}
$$

Following Filardo (1994), the transition probabilities are non-negative and vary between zero and one. For $\theta>0$, a high level in $x_{\mathrm{t}-1}$ implies that the equity returns are more likely to stay in regime 0 .Conversely, $\theta<0$ implies that a switch to the high volatility state is more likely following a high level in $x_{\mathrm{t}-1}$.

\section{Data description}

The empirical analysis is carried out using monthly data for the USA for the period of January 1990 to December 2016. We employ real stock returns for the S\&P500 that are obtained from Robert Shiller's website ${ }^{1}$ and inflation rates from International Monetary Fund (IMF). The inflation rate is defined as $\pi_{t}=100 \times\left(\ln \left(c p i_{t}\right)-\ln \left(c p i_{t-1}\right)\right)$, where the $c p i$ is the consumer price index. The real stock returns are defined as follows:

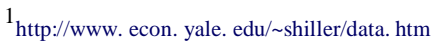




$$
r_{t}=100 \times \ln \left(\frac{P_{t}}{P_{t-1}}\right)
$$

Where $P_{t}$ is the real share price index $(\mathrm{t})$, generated by deflating the logarithm of nominal share price index by the logarithm of the consumer price index (cpi).

Table 1 reports some monthly descriptive statistics for the S\&P500 real stock returns and the inflation rate. As it can be observed, the standard deviations are significantly higher than the mean, implying that the S\&P500 real stock returns have higher levels of volatility. Skewness tests indicate that distributions are significantly skewed to the left. In addition, high excess kurtosis values suggest that the series distributions are highly leptokurtic relative to the normal distribution. According to the Jarque-Berra test, it is evident to note that the hypothesis of normal distribution is rejected at the $1 \%$ significance level for both the series. Furthermore, Table 1 reports unit root and stationary test results. Unit Root tests are the Augmented Dickey and Fuller (1979) and the Phillips and Perron (1988) tests. The obtained results reveal that the S\&P500 real stock returns and the inflation rate time series are stationary at the $1 \%$ significance level.

Table 1: Sample summary statistics for the monthly data of the S\&P500 real stock returns and the inflation rate

\begin{tabular}{|c|c|c|}
\hline & S\&P500 real stock returns & Inflation rate \\
\hline Minimum & -0.839 & -9.462 \\
\hline Maximum & 0.527 & 4.821 \\
\hline Mean & 0.0862 & 0.169 \\
\hline Standard Deviation & 0.144 & 1.558 \\
\hline Skewness & -1.0218 & -1.165 \\
\hline Kurtosis & 8.687 & 8.234 \\
\hline Jarque-Bera statistic & 491.574 & 441.944 \\
\hline Augmented Dickey-Fuller Test & $-11.8945^{* * *}$ & $-10.2205^{* * * *}$ \\
\hline Phillips-Perron test & $-14.3713^{* * * *}$ & $-9.85001^{* * * *}$ \\
\hline
\end{tabular}

Notes: $(* * *)$ indicates significance at the $1 \%$.

\section{Empirical results}

The Estimation results of univariate FITGARCH $(1,1)$ and MSFITGARCH models with fixed transition probabilities (Model 1, Model 2 and Model 3) and with explained transition probabilities (Model 4) are displayed in Table 1. 
Mohsen Khezri, Reza Ghazal, Somayeh Shokravi

Table 2: Estimation results of univariate FITGARCH $(1,1)$ and two-regime MS-FITGARCH $(1,1)$ models

\begin{tabular}{|c|c|c|c|c|c|}
\hline \multicolumn{6}{|c|}{ 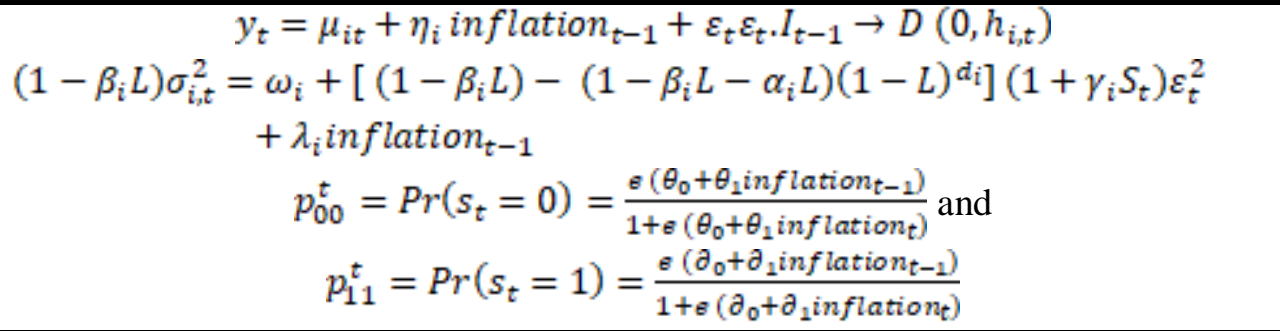 } \\
\hline \multirow{2}{*}{\multicolumn{2}{|c|}{ FITGARCH }} & \multicolumn{4}{|c|}{ MS-FITGARCH } \\
\hline & & Model 1 & Model 2 & Model 3 & Model 4 \\
\hline $\begin{array}{l}\text { Log Likelihood } \\
\text { LR }\end{array}$ & -560.55 & $\begin{array}{l}-550.917 \\
19.266^{* * *}\end{array}$ & $\begin{array}{l}-547.053 \\
7.734^{* * * *}\end{array}$ & $\begin{array}{c}-547.420 \\
6.99^{* * * *}\end{array}$ & -552.940 \\
\hline$\mu_{0}$ & $\begin{array}{c}0.312^{* * * *} \\
(4.49)\end{array}$ & $\begin{array}{c}0.445^{* * * *} \\
(5.163)\end{array}$ & $\begin{array}{c}0.567^{* * * *} \\
(6.882)\end{array}$ & $\begin{array}{c}0.566^{* * * *} \\
(5.992)\end{array}$ & $\begin{array}{r}0.602^{* * * *} \\
(5.334)\end{array}$ \\
\hline$\eta_{0}$ & & & $\begin{array}{c}-1.717^{* * *} \\
(-3.518)\end{array}$ & $\begin{array}{r}-1.727^{* * * *} \\
(-3.351)\end{array}$ & $\begin{array}{r}-2.242^{* * * *} \\
(-4.061)\end{array}$ \\
\hline$\omega_{0}$ & $\begin{array}{c}0.711^{* * *} \\
(3.68)\end{array}$ & $\begin{array}{r}0.808^{* * * *} \\
(7.309)\end{array}$ & $\begin{array}{c}0.737^{* * * *} \\
(4.169)\end{array}$ & $\begin{array}{c}0.802^{* * * *} \\
(4.583)\end{array}$ & \\
\hline$d_{0}$ & $\begin{array}{c}0.941^{* * * *} \\
(3.61)\end{array}$ & $\begin{array}{l}0.004 \\
(0.616)\end{array}$ & & & \\
\hline$Y_{0}$ & $\begin{array}{l}0.126 \\
(0.314)\end{array}$ & $\begin{array}{l}9.139 \\
(0.712)\end{array}$ & & & \\
\hline$\beta_{0}$ & $\begin{array}{l}0.075 \\
(0.322)\end{array}$ & $\begin{array}{l}-0.018 \\
(-0.812)\end{array}$ & $\begin{array}{l}0.893^{* * *} \\
(19.594)\end{array}$ & $\begin{array}{l}0.896^{* * *} \\
(16.549)\end{array}$ & $\begin{array}{l}0.935^{* * *} \\
(40.007)\end{array}$ \\
\hline$\alpha_{0}$ & $\begin{array}{c}0.818^{* * *} \\
(8.827)\end{array}$ & $\begin{array}{c}-0.052 \\
(-0.955)\end{array}$ & $\begin{array}{l}0.841^{\text {**** }} \\
(14.092)\end{array}$ & $\begin{array}{l}0.846^{* * *} \\
(12.575)\end{array}$ & $\begin{array}{l}0.867^{* * *} \\
(22.840)\end{array}$ \\
\hline$\lambda_{0}$ & & & $\begin{array}{c}0.596 \\
(0.561)\end{array}$ & & \\
\hline$\theta_{0}$ & & $\begin{array}{l}3.387^{* * *} \\
(10.926)\end{array}$ & $\begin{array}{r}-1.687^{* * *} \\
(-3.725)\end{array}$ & $\begin{array}{l}-3.434^{* *} \\
(-2.062)\end{array}$ & $\begin{array}{l}1.511^{* * *} \\
(2.282)\end{array}$ \\
\hline$\theta_{1}$ & & & & & $\begin{array}{l}-3.453 \\
(-1.128)\end{array}$ \\
\hline$\mu_{1}$ & & $\begin{array}{l}-0.603 \\
(-1.093)\end{array}$ & $\begin{array}{l}-1.019 \\
(-1.544)\end{array}$ & $\begin{array}{l}-0.967 \\
(-1.332)\end{array}$ & $\begin{array}{l}-0.344 \\
(-0.648)\end{array}$ \\
\hline$\eta_{1}$ & & & $\begin{array}{l}0.515 \\
(0.281)\end{array}$ & $\begin{array}{c}0.145 \\
(0.094)\end{array}$ & $\begin{array}{l}2.163 \\
(1.242)\end{array}$ \\
\hline$\omega_{1}$ & & $\begin{array}{r}2.132^{* * * *} \\
(4.757)\end{array}$ & $\begin{array}{r}2.924^{* * * *} \\
(2.958)\end{array}$ & $\begin{array}{c}2.327^{* * *} \\
(5.082)\end{array}$ & \\
\hline$d_{1}$ & & $\begin{array}{l}0.010 \\
(0.444)\end{array}$ & & & \\
\hline$\gamma_{1}$ & & 40.223 & & & \\
\hline
\end{tabular}




\begin{tabular}{cccccc}
\hline & & & & \\
$\beta_{1}$ & & $(0.366)$ & & & \\
& & $0.638^{* * *}$ & $0.951^{* * *}$ & 0.707 & $1.108^{* * *}$ \\
$\alpha_{1}$ & & $(5.298)$ & $(9.934)$ & $(0.920)$ & $(7.681)$ \\
& & $0.648^{* * * *}$ & $0.975^{* * *}$ & 0.733 & $0.892^{* * * *}$ \\
$\lambda_{1}$ & & $(4.957)$ & $(18.871)$ & $(0.929)$ & $(12.049)$ \\
& & & -4.717 & & \\
$\partial_{0}$ & & & $(-0.522)$ & & \\
& & $-2.089^{* * *}$ & $3.258^{* * *}$ & 1.839 & 2.873 \\
$\partial_{1}$ & & $(-4.358)$ & $(5.735)$ & $(0.705)$ & $(0.453)$ \\
$Q(12)$ & 15.9905 & 16.1794 & 14.545 & 15.0474 & 19.441 \\
$Q^{2}(12)$ & {$[0.192]$} & {$[0.183]$} & {$[0.267]$} & {$[0.239]$} & {$[0.078]$} \\
$p_{00}$ & {$[0.3645$} & 12.097 & 9.8589 & 11.3945 & 5.7255 \\
$p_{11}$ & & {$[0.438]$} & {$[0.628]$} & {$[0.495]$} & {$[0.929]$} \\
\hline
\end{tabular}

Notes: Figures in the parentheses are the t-values, $\left(^{* * *}\right),\left({ }^{* *}\right)$ and $\left(^{*}\right)$ indicate significant the 1\%, 5\% and 10\% significance levels, respectively. The LR test statistic approximately follows a $\chi^{2}$ distribution. $Q$ (12) and $Q^{2}$ (12) is the Ljung-Box test, the null hypothesis is no serial correlations in the residuals and squared residuals at lag 10.P-value are displayed in brackets [].

The autoregressive order in the mean equation was determined to be zero and for the variance equation, the FITGARCH $(1,1)$ fits the data well.

Model 1: MS-FITGARCH model with fixed transition probabilities; Model 2: Incorporating the inflation variable into the mean and variance equation in MSGARCH model with fixed transition probabilities; Model 3: Incorporating the inflation variable into the mean equation in MS-GARCH model with fixed transition probabilities. Model 4: MS-GARCH model with explained transition probabilities.

\section{1. MS-FITGARCH model with fixed transition probabilities}

In this subsection, we discuss the estimation results of the univariate tworegime MS-FITGARCH $(1,1)$ model with fixed transition probabilities for the real stock returns. By using the Likelihood Ratio (LR) test proposed by Garcia and Perron (1996), we test the null hypothesis $\left(H_{0}\right)$ of no switching in stock market volatilities determined by a univariate $\operatorname{FITGARCH}(1,1)$ process against the alternative hypothesis $\left(H_{1}\right)$ implying a univariate MS-FITGARCH with having constant transition probabilities (Model 1) switching in the stock market volatilities. The statistic of LR test is calculated by $\mathrm{LR}=2 \mid \mathrm{ln}$ LMS-FITGARCH-ln 
LFITGARCH| and the critical value is in accordance to Davies (1987) P-value, suggested by Garcia and Perron (1996). According to Table (2), the statistic of LR test for Model 1 is estimated at 19.266 at a significance level of $1 \%$, confirming the existence of two regime shifts in stock market volatilities. On this basis, the real stock returns can be fitted by a two-regime MS-FITGARCH model suitably. These results are consistent with the Henrry (2009) and Aloui and Jammazi (2009) studies.

The intercept of the conditional variance in regime 2 is lower than regime 1: the average return during recession $\left(\mu_{0}\right)$ in each month is estimated at 0.445 which is significantly different from regime 2 at -0.603 , though the latter is insignificant. The intercept in the conditional variance equation, $\omega$, is significant as well.

The smoothed and filtered probabilities for MS-FITGARCH model for two regimes of the real stock return are plotted in figure 1 to allow us to interpret two different conditional probabilities properly. Two regimes can be observed: first, a regime of behavior of stock markets in expansion with high expected return and low volatilities, and second, a regime of stock market behavior in recession with low expected return and high volatilities.

In FITGARCH model, $\beta$ which captures the persistence in conditional variance is only significant under regime 2 of the real stock return. The fractional difference parameter $d$ is not significant under both regimes, implying that there is no evidence of long-memory on the real stock return series under regime switching. Moreover in both regime 1 and regime 2, asymmetrical effects of coefficients $Y$ for stock market return are not also significant, implying that the S\&P 500 would not react differently to negative innovations to returns than positive innovations of equal size and vice versa. This result reduces FITGARCH model to the usual GARCH model. The results of estimating transition probabilities $\mathrm{p}_{00}$ and $\mathrm{p}_{11}$ are highly significant for real stock return. Based on the estimated values for these probabilities, it can be said that it is more likely for stocks to stay in regime 1 ( $\mathrm{p}_{00}$ about 0.967 ) than regime 2 ( $\mathrm{p}_{11}$ about 0.89 ). In addition, high magnitude for these probabilities simply that only a large incident can transfer stock return or series of return volatilities from one regime to the other (and vice versa).

Based on the results of Box-Pierce test (B-P) of order 12 for checking white noise of the residuals, there is no serials correlation in the squared residuals, confirming the non-existence of heteroscedasticity of residuals. The results show that Markov switching model offers 2 regimes with acceptable approximation of the heteroscedasticity. 

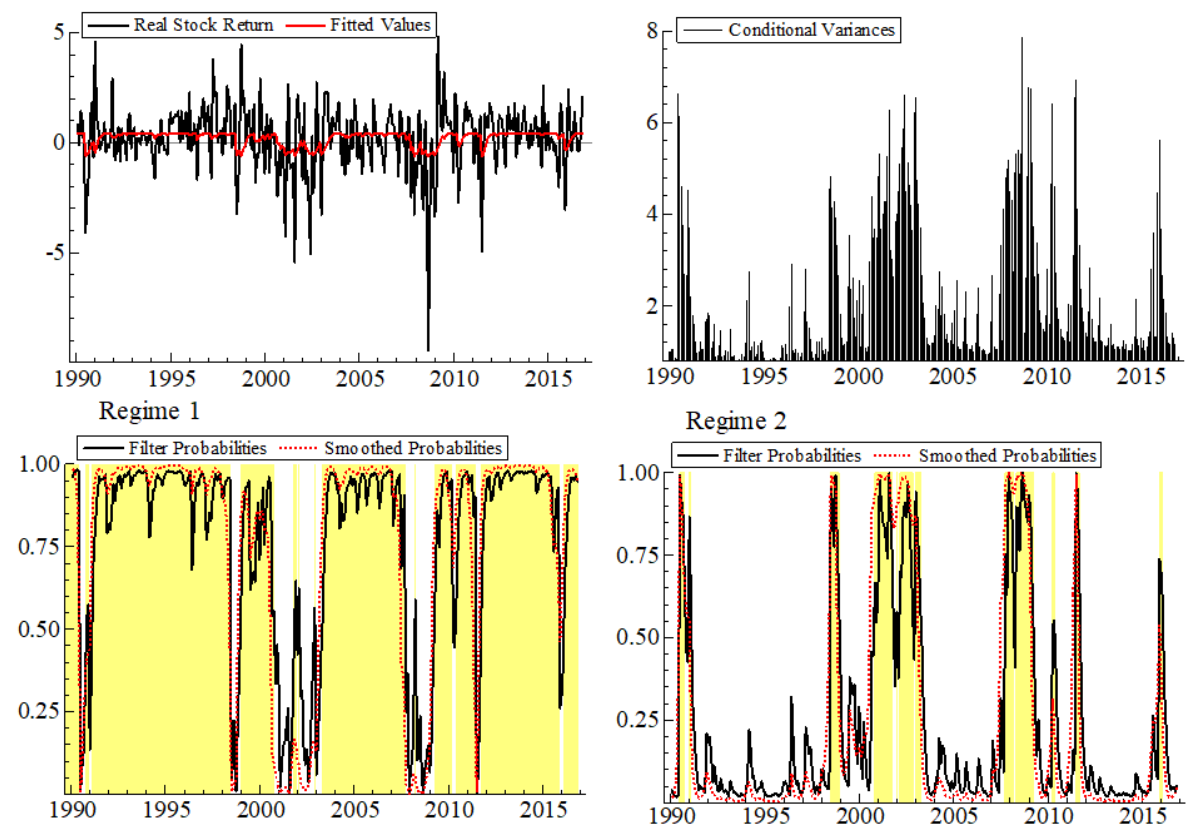

Figure1. Smoothed and filtered probabilities of MS-FITGARCH model with fixed transition probabilities.

Observing from figure 1, it can be seen that the MS-FITGARCH model is performing well in capturing the changes in stock return series under both regimes. It displays clearly the variance switches corresponding to a high return-low volatility state (expansion phase) under regime 1 and a low return-high volatility state (recession phase) under regime 2.

\section{2. Incorporating the inflation variable into MS-GARCH model with fixed transition probabilities}

We bring the first lag of inflation variable (inflation in-1 $_{\text {) }}$ ) into the mean and variance equation of MS-GARCH model with fixed transition probabilities (Model 2). Estimation results of the model are presented in Table 1. According to the results, the estimated coefficient on the first lag of inflation is not statistically different from zero in the variance equation. Therefore, the MS-GARCH model is extended through fixed transition probabilities only in the mean equation (Model 3). To determine whether inflation rate has any impact on the real stock return, likelihood ratio of Model 1 and Model 3 is compared, corresponding to the cases of existence and non-existence of first lag of inflation in the mean equation, respectively. The statistic of LR test for comparing two models is estimated at 6 . 99 at a significance level of $1 \%$, confirming that inflation has a significant impact on the mean of the real stock return. 
The estimated coefficient of inflation $_{t-1}$ in regime 1 with low variancehigh mean (expansion phase) is negative and significantly different from zero $\left(\eta_{0}=-1.72\right)$, while under regime 2 with high variance-low mean (recession phase) the coefficient is not significantly different from zero. These results indicate the asymmetrical impacts of inflation rate on stock return under the two recession and expansion regimes. The Box Pierce (B-P) diagnostic test with the order of 12 in Model 3 indicates that the null hypothesis $\left(H_{0}\right)$ of no serials correlation in the squared residuals is not rejected; an indication of lack of heteroscedasticity of residuals. Figure 2 presents the smoothed probabilities for MS-FITGARCH $(1,1)$ model with fixed transition probabilities by incorporating inflation $_{t-1}$ in the mean equation.
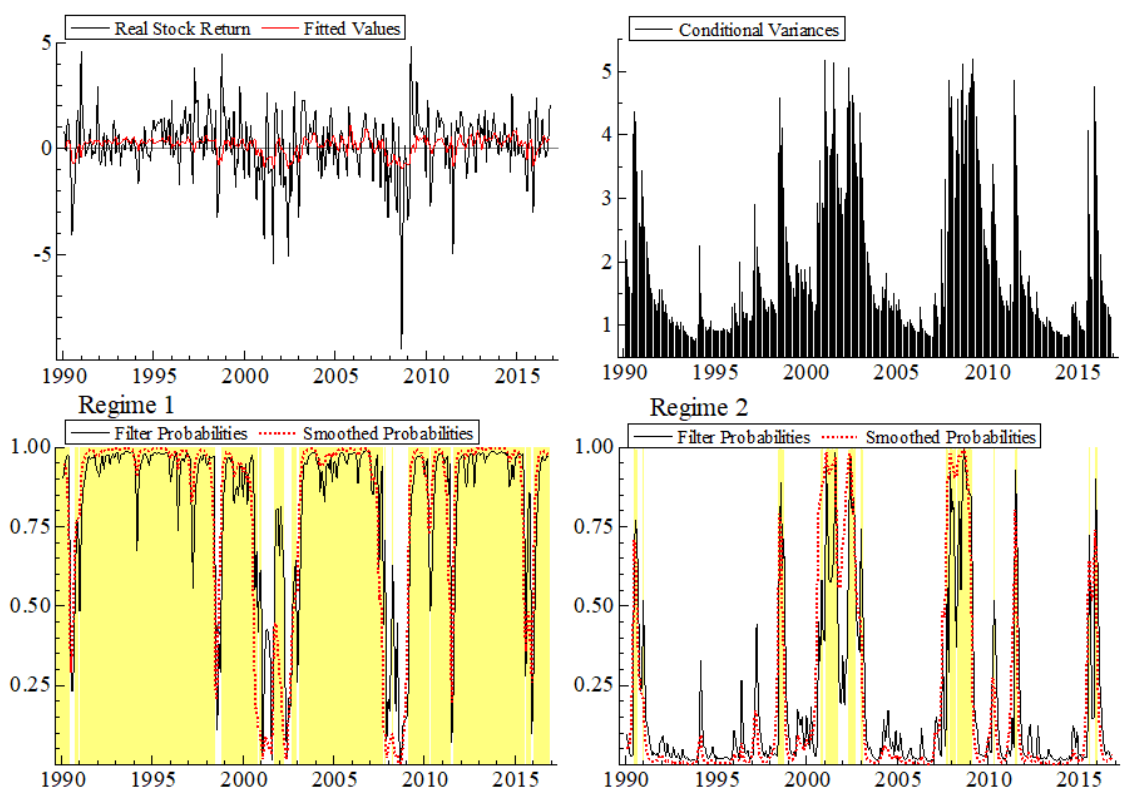

Figure 2. Smoothed and filtered probabilities of MS-FITGARCH (1, 1) model with fixed transition probabilities by incorporating inflation $_{t-1}$ in the mean equation

Based on figure 2, clear variance switching corresponding to a high returnlow volatility state (expansion phase) under regime 1 and a low return-high volatility state (recession phase) under regime 2 are observed. Clearly this model provides a better approximation of the heteroscedasticity andcaptures recession and expansion phasesbetter than the unvariate MS-GARCH model in figure 1. 


\section{3. MS-GARCH model with explained transition probabilities}

By including the first lag of inflation in the model, we can investigate whether any fluctuations in inflation $_{t-1}$ will vary the probabilities of regimes overtime or not. Moreover, it allows us to test whether the regime-switching probabilities change across volatility regimes or not. To this end, MS-GARCH model is extended through explained transition probabilities (Model 4). To ensure a more direct comparison between the fixed transition probabilities and explained transition probabilities models, the LR test is used.

As reported in last column of Table 1, the log-likelihood of the MSGARCH $(1,1)$ model with explained transition probabilities is not significantly larger than the simple MS-GARCH $(1,1)$ model with fixed transition probabilities, and therefore, we accept the null hypothesis of fixed transition probabilities rather than the MS-GARCH with explained transition probabilities specification at the $10 \%$ significance level. This implies that there is evidence of regime-independence response of real stock market return volatilities to inflation rate. According to the results, the estimated coefficients of first lag of inflation in model MS-GARCH (1, 1) with the explained transition probability equation in regime 1 and regime 2 , the coefficients $\partial_{1}$ and $\theta_{1}$ are not statistically significant at $10 \%$ level. This implies that inflation $_{t-1}$ does not affect the probability of staying in each regime and can be omitted from the model.

\section{Summary and concluding remarks}

In this paper we studied the role of stock market volatilities in explaining the stock markets behavior using monthly data over 1990 to 2016 fo the US economy. The empirical approach of this study is based on a two-regime MSFITGARCH $(1,1)$ model. According to the results, the MS-FITGARCH model with switching in the mean and in the variance offers a better statistical fit to the data, compared to the other alternatives. The results suggest that real stock returns display significant evidence of regime switching; The first regime is consistent with a high return-low volatility state (expansion phase) and the second regime is consistent with a low return- high volatility state (recession phase).

Results clearly indicate that there is no evidence of having long-memory in the real stock return series under regime switching, since the long-run characteristics of volatility is insignificant under both regimes. Also the results show that the S\&P 500 would not react much differently to negative innovations to returns than positive innovations of equal size and vice versa. This result reduces FITGARCH model to the usual GARCH model for modeling the real stock return series under switching in regimes.

According to the results, estimated coefficients on fist lag of inflation in the mean equation under the recession phase is not significantly different from zero, confirming the Fisher hypothesis (1930) on non-existence of relationship 
Mohsen Khezri, Reza Ghazal, Somayeh Shokravi

between the real stock returns and expected inflation in recession phase of the real stock returns. However, there is a statistically negative relationship in expansion phase. The Several studies show that the stock return-inflation relation depends on the source of inflation (e. g. Danthine and Donaldson, 1986; Lee, 1989). That is, a positive association between stock returns and real activity, combined with a negative association between inflation and real activity based on a money demand model, leads to spurious negative relations between stock returns and inflation. Our results confirmed that the source of inflation in expansion phase is more related to monetary factors instead of non-monetary factors such as real output shocks.

The results demonstrate inflation rate asymmetrical impacts on stock return under the two recessions and expansion regimes. We notice that the first lag of inflation doesn't affect the probability of staying in expansion or recession phases and can be omitted from the model, implying that inflation isn't a critical variable in explain the structural changes of the stock returns.

\section{REFERENCES}

[1] Aloui, C., Jammazi, R. (2009), The Effects of Crude Oil Shocks on Stock Market Shifts Behavior: A Regimes Witching Approach; Energy Economics, 31 (5): 789-799;

[2] Baillie, R. T., Bollerslev, T., Mikkelsen, H. O. (1996), Fractionally Integrated Generalized Autoregressive Conditional Heteroskedasticity; Journal of Econometrics, 74: 3. 30;

[3] Black, F. (1976), Studies of Stock Market Volatility Changes. Proceedings of the American Statistical Association, Business and Economic Statistics Section:

177-181;

[4] Bollerslev, T. P. (1986), Generalized Autoregressive Conditional

Heteroskedasticity; Journal of Econometrics, 31: 307-327;

[5] Bollerslev, T. P. (1987), A Conditional Time Series Model for Speculative

Prices and Rates of Returns; Review of Economics and Statistics, 69, 524-554;

[6] Danthine, J. P., Donaldson, J. (1986), Inflation and Asset Prices in an

Exchange Economy; Econometrica, 54: 585-606;

[7] Fama, E. F. (1981), Stock Returns, Real Activity, Inflation, and Money;

American Economic Review, 71: 545-565;

[8] Filardo, A. J. (1994), Business-cycle Phases and their Transitional

Dynamics; Journal of Business and Economic Statistics, 12: 299-308;

[9] Filardo, A. J., Gorgon, S. F. (1998), Business Cycle Durations; Journal of

Econometric, 85: 99-123;

[10] Fisher, I. (1930), The Theory of Interest. New York7 MacMillan;

[11] Garcia, R., Perron, P. (1996), An Analysis of the Real Interest Rate under

Regime Shifts; Review of Economics and Statistics, 78: 111-125; 
[12] Hamilton, J. D. (1989), A New Approach to the Economic Analysis of Nonstationary Time Series and the Business Cycle; Econometrica, 57: 357-384; [13] Hamilton, J. D., Susmel, R. (1994), Autoregressive Conditional Heteroscedasticity and Changes in Regime; Journal of Econometrics, 64: 307333 ;

[14] Henry, O. (2009), Regime Switching in the Relationship between Equity Returns and Short-Term Interest Rates; Journal of Banking and Finance, 33: 405-414;

[15] Kryzanowski, L., Rahman, A. H. (2009), Generalized Fama Proxy Hypothesis: Impact of Shocks on Phillips Curve and Relation of Stock Returns with Inflation; Economics Letters, 103: 135-137;

[16] Lamoureaux, C., Lastrappes, W. (1990), Persistence in Variance, Structural Change and the GARCH Model; Journal of Business and Economic Statistics, 8: 225-234;

[17] Lee, B. S. (1989), Solving, Estimating and Testing a Nonlinear Stochastic Equilibrium Model with an Example of the Asset Returns and Inflation Relationship; Journal of Economic Dynamics and Control, 13: 499-531;

[18] Lopes, Sílvia R. C., Prass, Taiane S. (2014), Theoretical Results on Fractionally Integrated Exponential Generalized Autoregressive Conditional Heteroskedastic Processes; Physica A: Statistical Mechanics and its Applications, 401: 278-307;

[19] Modigliani, F., Cohn, R. A. (1979), Inflation Rational Valuation and the Market; Financial Analysts: 24-44;

[20] Nelson, D. B. (1990), Stationarity and Persistence in the $\operatorname{GARCH}(1,1)$ Model; Econometric Theory, 6: 318-334;

[21] Nelson, D. B. (1991), Conditional Heteroscedasticity in Asset Returns: A New Approach; Econometrica, 59: 347-370;

[22] Patrick, H. (1966), Financial Development and Economic Growth in Underdeveloped Countries; Economic development and cultural change, 12 (2): 174-89;

[23] Walid, C., Chaker, A., Masood, O., Fry, J. (2011), Stock Market Volatility and Exchange Rates in Emerging Countries: A Markov-State Switching Approach; Emerging Markets Review, 12: 272-292;

[24] Wang, P., Theobald, M. (2008), Regime-switching Volatility of Six East Asian Emerging Stock Markets; Research in International Business and Finance, 22: 267-283;

[25] Zakoian, M. (1994), Threshold Heteroscedastic Models; Journal of Economic Dynamics and Control, 18: 931-955. 